www.jmscr.igmpublication.org

Index Copernicus Value: 79.54

ISSN (e)-2347-176x ISSN (p) 2455-0450

crossref DOI: https://dx.doi.org/10.18535/jmscr/v7i4.192

Journal Of Medical Science And Clinical Research

IGM Publication

An Official Publication of IGM Publication

\title{
Diagnostic Laparoscopic for Subfertility and PCO
}

\author{
Authors \\ Dr Md Mahamudur Rahman ${ }^{*}$, Dr Md Mujibur Rahman², \\ Dr Mosammat Ferdousi Akhter ${ }^{3}$ \\ ${ }^{1}$ Professor, Gynae \& Obs, Patuakhali Medical College (PkMC), Bangladesh \\ ${ }^{2}$ Assistant professor, Gynae \& Obs, Patuakhali Medical College (PkMC), Bangladesh \\ ${ }^{3} \mathrm{Jr}$ Consultant, 250-Bed Patuakhali General Hospital, Bangladesh \\ *Corresponding Author \\ Dr Md Mahamudur Rahman \\ Professor, Gynae \& Obs, Patuakhali Medical College (PkMC), Bangladesh
}

\begin{abstract}
For women, problems with impregnation arise mainly from either operational problem in the Fallopian tube or uterus or problems regarding releasing eggs. Polycystic Ovary Syndrome (PCOS) is a health problem that affects 1 in 10 women of child rearing age. PCOS is also now a common and treatable cause of subfertility. To find out the diverse types of pelvic pathologies, female subfertility along with PCOS may be treated through Diagnostic Laparoscopy where a small incision is made in the abdomen which is a thin laparoscope which is a flexible microscope with a light at the end is inserted through it.

Objectives: To reassess the importance of Diagnostic laparoscopy in subfertility investigation treatment plan determination.

Methods: This study was carried out in Government and Private Hospital at Patuakhali, Bangladesh. The study enrolled 100 patients with subfertility problems who attended in that institution during the study time. The institution was chosen because of its available facilities for the infertile women and patient with PCOS and other subfertility related diseases. Female patient's, who have significant infertile condition due to abdominal abnormalities, PCOS, endometriosis and others, assessment was carried out before starting the endoscopic procedures followed by thorough general, abdominal and pelvic examinations then Laparoscopy was performed under general anaesthesia.

Results: Patient's age ranged from 18 to 42 years and with subfertility duration $>1$ year were selected as study sample. The study was conducted on 100 female patients with problems regarding subfertility. Uterine pathology data shows that $12 \%$ of the selected patients had enlarged uterus and the uterus of $8 \%$ had smaller than normal sized uterus. Ovarian pathology data shows $32 \%$ patients had normal ovaries, $12 \%$ had peri-ovarian adhesions, $42 \%$ had polycystic ovaries (PCO), and 1\% had small ovaries. $2 \%$ patient had tubo-ovarian mass, $8 \%$ had simple cysts while $3 \%$ of the patients had chocolate cysts. Tubal pathology data shows 66 patients (66\%) had normal tubes. 10 patients (10\%) had some form of peri-tubal adhesion. 17 patients (17\%) had tubal block. Amongst them 9\% patients had unilateral block and $8 \%$ patients had bilateral tubal block. 2 patients (2\%) had hydrosalpinx and 2 patients (2\%) had tubo-ovarian mass. The tubes could not be visualized in 3 cases due to gross adhesions. Peritoneal pathology data shows $16 \%$ had pelvic adhesions and $10 \%$ had endometriosis.

Conclusion: This study helps to re-evaluate the controversial means concerning the use of laparoscopy in subfertility work-up, the findings in the study provides a clear description of the abnormal circumstances that motivates changes in intended initial treatment plan for infertile men and women.

Keywords: Laparoscopy, Ovary, Infertility, Uterus, Fallopian tube.
\end{abstract}




\section{Introduction}

At present, infertility is no longer applicable to use as it should be referred as subfertility. The Oxford Dictionary defines 'infertility' as "not capable of producing offspring; barren". However, with the developments in treatment over the last thirty years, the development of IVF, application of testicular biopsy, the usage of intracytoplasmic sperm injection (ICSI), oocyte donation, sperm donation and surrogacy, there is no couple who does not have the possibility to conceive, thus the term 'infertility' should no longer be used. The probability of conception rests on the success rate of the particular treatment and the number of sequences of treatment that a couple accept.

Diagnostic laparoscopy which is also known as female pelvic laparoscopy is a surgical procedure where doctors use required tools to view a woman's reproductive organs. Laparoscopy may be used to diagnose sub or infertility or to treat a fertility problems' like the Polycystic Ovary Syndrome (PCOS). It is a situation faced by women which characterized by irregular or no menstrual periods, obesity, acne, and excess hair growth. PCOS is a illness of chronically nonstandard ovarian function and hyperandrogenism (abnormally elevated androgen levels). It affects 5-15\% of women of reproductive age.

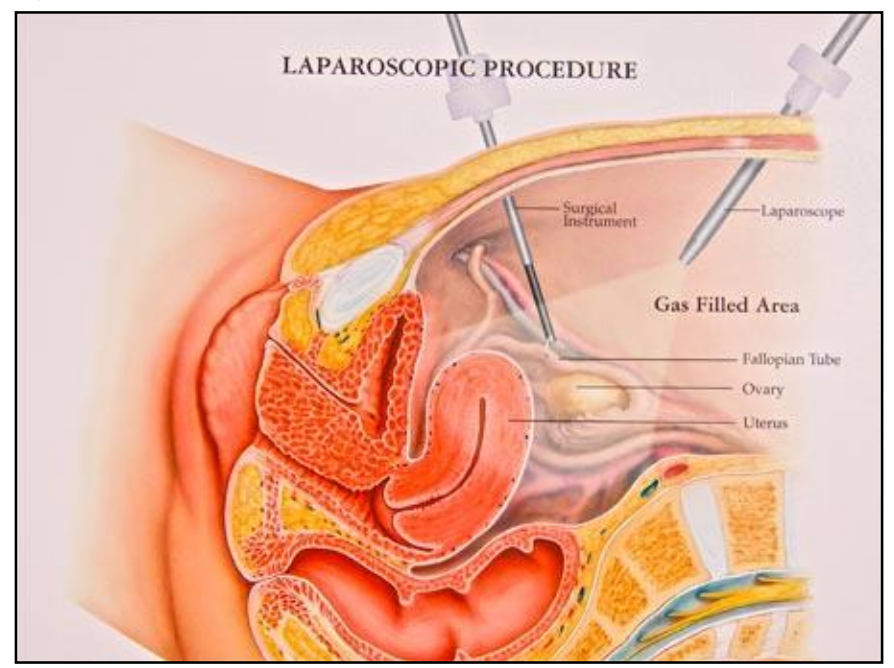

Figure 1: Laparoscopic procedure

Not diagnostic laparoscopy should be conducted in women with infertility is controversial. A female pelvic laparoscopy is often recommended when other diagnostic tests, such as ultrasound and X-ray, cannot find the cause of a symptom. Some causes of infertility can only be diagnosed through laparoscopy (e.g. Endometriosis). In fact, there is insufficient evidence to support the positive effect of surgical treatment of endometriosis and PCOS in early stages, because of lack definitive recommendation. The aim of this study was reassess the importance of laparoscopy in subfertility investigation and its role in determining change in the initial treatment plan.

\section{Objective of this study}

The main objective for this study is to reassess the importance of Diagnostic laparoscopy in subfertility investigation for treatment plan determination.

The specific objectives are:

$>$ Find the cause of pain in the pelvic and abdominal regions

$>$ Examine a tissue mass

$>$ Confirm endometriosis or pelvic inflammatory diseases

$>$ Look for blockage of the fallopian tubes or for other causes of subfertility

\section{Methodology}

Study Type: This was a cross sectional, descriptive and analytical study.

Place of the study: The study was carried out in Government and Private Hospital, Patuakhali, Bangladesh. The study duration was two years. The study enrolled 100 infertile patients who attended in the hospitals. The hospitals were chosen with all available facilities for the infertile women and patient with PCOS and other infertility related diseases.

Inclusion Criteria: The inclusion criteria for this study are female patients who have significant infertile condition due to abdominal abnormalities where the mean age ranged from 18 to 42 years and also all the infertile conditions were result of PCOS, endometriosis and others with infertility duration of $>1$ year. 
Exclusion Criteria: The exclusion criterion for the study was that the patients were noncommunicable, non-cooperative and with serious medical condition from that she was unable to communicate with the researcher/interviewer.

Study Population and Sample Size: All the patients who came for consultation to the clinic, during the study period, and who were fulfilled the inclusion criteria were underwent a full infertility investigation after the initial visit. 100 female patients were chosen as the sample for the study. The female evaluation included screening for infectious disease, transvaginal ultrasound, hormone parameter, hysterosalpingography, and laparoscopy.

\section{Ethical Consideration}

The aims and the objectives of the study along with its procedure, diagnostic methods, risks and benefits for the study were explained to the patients and their relatives in understandable local language.

\section{Pre-testing}

Assessment of these patients was carried out carefully before starting the endoscopic procedures. A full history was taken which was followed by thorough general, abdominal and pelvic examinations.

\section{Data processing and analysis}

- After collecting the data, it was checked and data analysis was performed by statistical package for social science (SPSS) software.

- Data was edited, verified and entered into the computer.

- Result was presented as text, tables, and figures.

- Statistical calculations were performed by computer program.

\section{Results}

Table 1 describes the age of the selected patients. Two patients $(2 \%)$ were in the range of 18 to 20 years of age. Sixty-nine patients $(69 \%)$ were aged between 21 to 30 years. The age of the other 27 patients (27\%) ranged from 31 to 40 years whereas only 1 patient (1\%) of the study was aged 42 years.

Table 1: Age Demographic of Patients

\begin{tabular}{|c|c|c|}
\hline $\begin{array}{c}\text { Age of } \\
\text { Patients }\end{array}$ & $\begin{array}{c}\text { Number of } \\
\text { Patients }\end{array}$ & Percentage \\
\hline 18-20 years & 2 & $2 \%$ \\
\hline 21-30 years & 69 & $69 \%$ \\
\hline 31-40 years & 27 & $27 \%$ \\
\hline 42 years & 1 & $1 \%$ \\
\hline Sum & $\mathbf{1 0 0}$ & $\mathbf{1 0 0 \%}$ \\
\hline
\end{tabular}

In the uterine pathology side $66(66 \%)$ patients had normal uterus. 12 patients $(12 \%)$ had enlarged uterus while the 8 patients' $(8 \%)$ had smaller than normal sized uterus. Amongst them 9 (9\%) had myomas, the mobility of the uterus was restricted in $11(11 \%)$ patients, congenital anomaly in the form of unicornuate and bicornuate uterus was seen in 1 patients $(1 \%)$, and the uterus could not be visualized due to gross adhesion in 2 cases (2\%). (Figure-2)

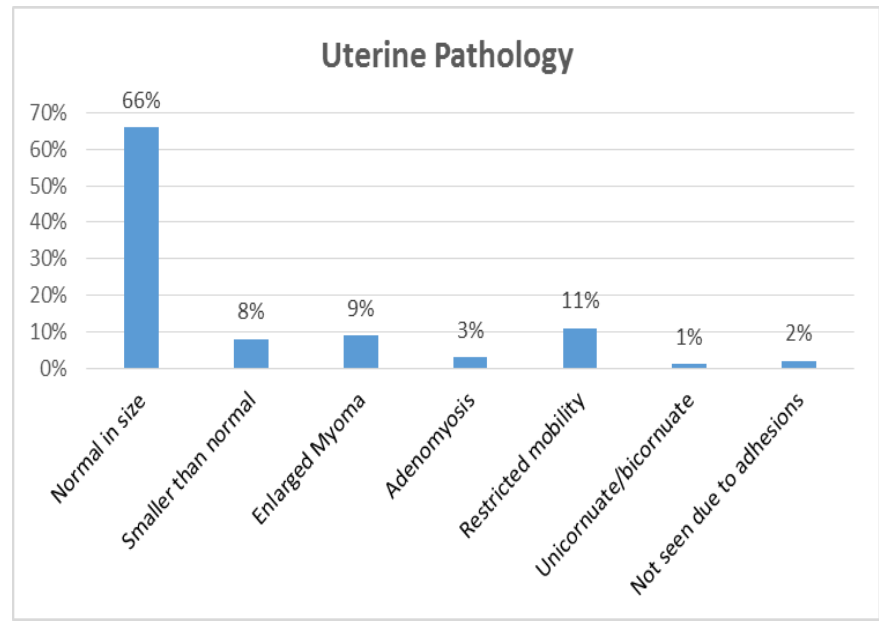

Figure 2: Uterine pathology

Table 5 shows ovarian pathology where $32 \%$ patients had normal ovaries. $12 \%$ had periovarian adhesions, $42 \%$ had polycystic ovaries (PCO), and $1 \%$ had small ovaries. $2 \%$ patient had tubo-ovarian mass, $8 \%$ had simple cysts while $3 \%$ of the patients had chocolate cysts. 


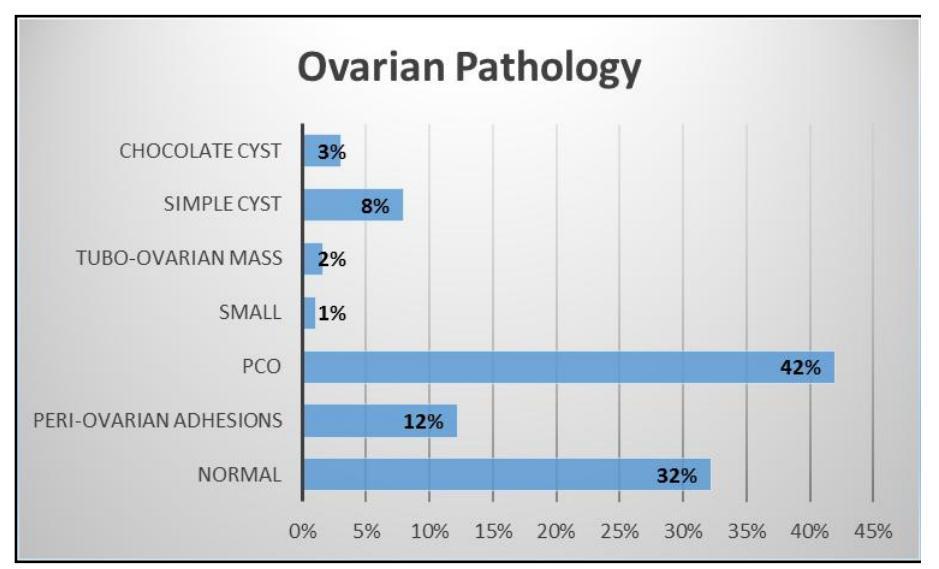

Figure 3: Ovarian pathology of Patients

In case of tubal pathology, 66 patients $(66 \%)$ had normal tubes. 10 patients (10\%) had some form of peri-tubal adhesion. 17 patients $(17 \%)$ had tubal block. Amongst them 9\% patients had unilateral block and $8 \%$ patients had bilateral tubal block. 2 patients (2\%) had hydrosalpinx and 2 patients (2\%) had tubo-ovarian mass. The tubes could not be visualized in 3 cases due to gross adhesions. (See Table-2)

Table 2: Tubal pathology of Patients

\begin{tabular}{|l|c|c|c|}
\hline $\begin{array}{l}\text { Laprosscopic } \\
\text { Findings }\end{array}$ & $\begin{array}{c}\text { Number } \\
\text { of Patients }\end{array}$ & Percentage \\
\hline Normal tubes & & 66 & $66 \%$ \\
\hline Peritubal adhesions & & 10 & $10 \%$ \\
\hline \multirow{3}{*}{ Tubal block } & Unilateral & 9 & $9 \%$ \\
\cline { 2 - 4 } & Bilateral & 8 & $8 \%$ \\
\hline Hydrosalpinx & & 2 & $2 \%$ \\
\hline Tubo-ovarian mass & & 2 & $2 \%$ \\
\hline \multirow{3}{*}{$\begin{array}{l}\text { Not seen due to } \\
\text { adhesion }\end{array}$} & Right & 1 & $1 \%$ \\
\cline { 2 - 4 } & Left & 1 & $1 \%$ \\
\cline { 2 - 4 } & Both & 1 & $1 \%$ \\
\hline
\end{tabular}

Table 4 shows peritoneal pathology where $74 \%$ of the patients had normal pelvic peritoneum, $16 \%$ patients had pelvic adhesions from PID and 10\% patients had endometriosis.

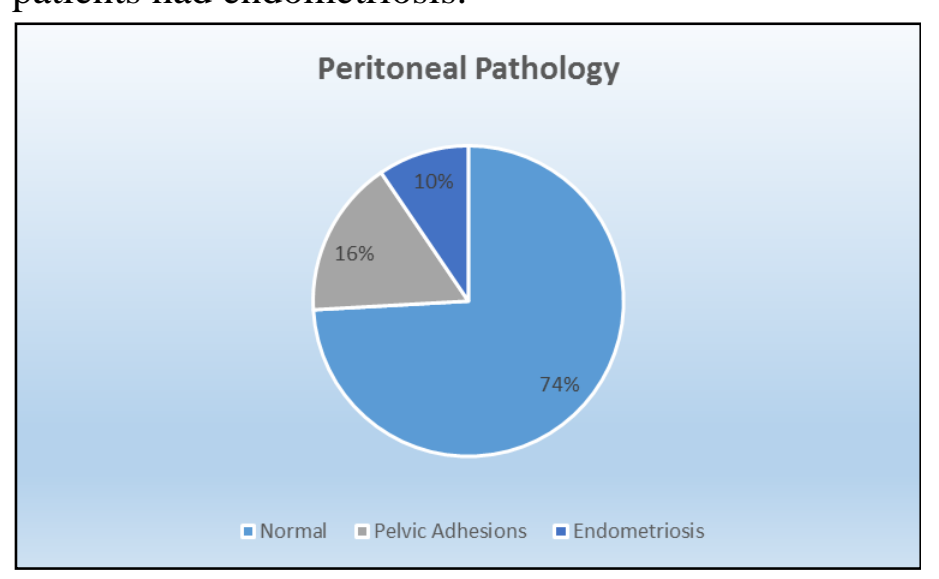

Figure 4: Peritoneal pathology of Patients

\section{Discussion}

This was a descriptive cross sectional and analytical study, which was conducted in the outpatient and inpatient at Government and Private Hospital, on patients who face such problem at conception. Since 1960, laparoscopy has gained widespread fame in gynaecologic practice. Since that time, this process has been used to diagnose unknown abdominal problems in order to follow the course of a known disease and to modify or give appropriate therapy ${ }^{[1]}$.

Past research advocates that outcomes even in singleton pregnancies, may be worse for women with assisted-conceptions when compared to their spontaneously conceived counterparts, small-forgestational age, low birth weight, including greater risks for preterm birth, caesarean delivery, and perinatal mortality ${ }^{[2][3][4]}$. The period of laparoscopy is one of the primary aspects of the discussion of the time at which a couple and the researcher may feel the investigation should proceed. The best treatment plan must be offered to an infertile or sub-fertile couple. In a young couple who have a negative history with conception, laparoscopy is usually suggested after all other tests are completed and in if the history suggests a pelvic factor or for older couples, it is often signposted as one of the primary approaches of evaluation ${ }^{[5]}$.

In this retrospective study laparoscopy was done in 100 patients with sub fertility problems where their physiological state and complaints varied. Another study of sub-fertile patients found, $66 \%$ with primary and $33 \%$ with secondary infertility which supports present study ${ }^{[6]}$.

In this study result showed that PCO was $42 \%$ which is noticeably higher than other studies; $6.7 \%$ (Adelusi et al) ${ }^{[7]}, 8.05 \%$ (Nabil et al) and ${ }^{[6]}$ and $15.6 \%$ (Aziz et al) ${ }^{[8]}$, which were also much lower than the present study. This disparity may be due to the fact that many of the patients were referred to this center for laparoscopy who failed ovulation induction. Ovarian cyst was found in $8 \%$ cases which is also higher than other study data $7.7 \%$ and $3.89 \%$ of the patients who had 
ovarian cysts (Adelusi et al, Nabil et al) ${ }^{[7,6]}$ From this study it can be understood that, Laparoscopy is very helpful to determine unsuspected pelvic pathology especially for PCO. It is a superior method to detect of pelvic adhesions, tubal obstruction, and endometriosis than other procedures. It was permitted in the development of concomitant accessory therapeutic procedures, thus signify the best treatment strategy for the subfertile couples. Laparoscopy is an essential step pre-tubal surgery which may also offer essential information concerning the nature and extent of future surgery. Due to the potential diagnostic and therapeutic aids, patients with unsolved subfertility should undergo diagnostic laparoscopy.

To re-evaluate the still contentious methods about the use of laparoscopy in subfertility work-up, the findings in the study provides a clear definition of the nonstandard conditions that motivates changes in the intended initial treatment plan.

\section{Conclusion}

Although no epidemiological study has been conducted in the national level to know the prevalence rate of subfertility in Bangladesh, The Total Fertility Rate (TFR) in Bangladesh was dropped markedly from 6.3 births each women in 1975 to 2.3 births each women in 2014. But there has been a vast improvement in the management of subfertility in the last 20 years. The coherent use of different drugs, surgery and laparoscopy technique holds the promise of a resolution for many sub-fertile couples. Laparoscopy is a vital and well-established procedure that can help these patients by diagnosing the precise cause of subfertility in time. But for clinician, it is also seen as a challenge to deploy these new techniques safely as well as effectively. Thus, adequate evaluation have to be applied before they are used in repetitive clinical practice.

\section{Reference}

1. Akhtarunnessa, T.A. Chowdhury, Ismat A., MD.L. K. Gazi, Banika B. Role of
Diagnostic Laparoscopy in Evaluation of Infertile Women, Bangladesh. Obstetrics and Gynaecology. 2013; Vol. 28(2): 88-91.

2. Jackson RA, Gibson $\mathrm{KA}, \mathrm{Wu} \mathrm{YW}$, Croughan MS. Perinatal outcomes in singletons following in vitro fertilization: a meta-analysis. Obstetrics \& Gynecology. 2004;103:551-63. [PubMed] [Google Scholar]

3. Helmerhorst FM, Perquin DAM, Donker D, Keirse MJNC. Perinatal outcome of singletons and twins after assisted conception: a systematic review of controlled studies. BMJ. 2004;328:261. [PMC free article] [PubMed] [Google Scholar]

4. Wang YA, Sullivan EA, Black D, Dean J, Bryant J, Chapman M. Preterm birth and low birth weight after assisted reproductive technology-related pregnancy in Australia between 1996 and 2000. Fertility and Sterility. 2005;83:1650-8. [PubMed] [Google Scholar]

5. Nabil,M. El-Tabbakh. Amin,A.M. (1994): Diagnostic laparoscopy in gynaecological problems : a retrospective study. OBGYN. net.

6. Adelusi, B. Al-Nuaim, L. and Makanjuola, D.(1995) : Diagnostic tubal patency. Fertil. Steril.,63(5) : 1016-1019.

7. Haider,G. Rani,S. Talpur,S. Zehra,N. Munir, A.(2010) : Laparoscopic evaluation of female infertility. J.Ayub Med. Coll. Abbottabad.,22(1):136-8.

8. Aziz, N. (2010) : Laparoscopic evaluation of female factors in infertility. J. Coll. Physicians. Surg.Pak. 20(10): 649-52. 